\title{
Premature coronary artery disease and the Prader-Willi syndrome
}

\author{
S.R. Page', S.S. Nussey', G.A. Haywood ${ }^{2}$ and J.S. Jenkins ${ }^{1}$ \\ Departments of ${ }^{1}$ Medicine and ${ }^{2}$ Cardiology, St George's Hospital Medical School, Cranmer Terrace, \\ London SW17 ORE, UK.
}

\begin{abstract}
Summary: A 28 year old woman with the Prader-Willi syndrome developed chest pain and loss of anterior $\mathbf{R}$ wave amplitude on the electrocardiogram. Cardiac catheterization demonstrated a severe proximal stenosis of the left anterior descending artery with delayed antegrade flow together with antero-apical akinesia consistent with myocardial infarction. Physicians involved in the management of patients with the Prader-Willi syndrome should be aware of this association with premature coronary artery disease.
\end{abstract}

\section{Introduction}

The Prader-Willi syndrome is a relatively common congenital disorder occurring with an incidence of 1 in 10,000 live births. ${ }^{1}$ The syndrome is characterized by poor fetal movements and breech presentation; hypotonia and delayed attainment of developmental milestones; hyperphagia and morbid obesity; small hands and feet; hypogonadism and mental retardation. ${ }^{1.2} \mathrm{~A}$ deletion from the long arm of chromosome 15 has been described in about $50 \%$ of cases. ${ }^{3}$ Premature coronary artery disease has been reported in only two previous cases of the Prader-Willi syndrome ${ }^{4,5}$ and in one report the diagnosis was only appreciated at post mortem. ${ }^{4}$ We report a third case in which coronary angiography demonstrated a severe proximal stenosis of the left anterior descending coronary artery in a 28 year old female with this syndrome.

\section{Case report}

A 28 year old female with the Prader-Willi syndrome attended an endocrine follow-up clinic. She complained of a single episode of severe constricting chest pain and breathlessness at rest two weeks previously. This had been followed by intermittent central chest pain of shorter duration, unrelated to exercise, and increasing breathlessness on exertion. There was no history of familial cardiac problems, diabetes or hypertension but she had smoked 5 cigarettes a day for 7 years. Her only medication was triiodothyronine $20 \mu \mathrm{g}$ three times daily for control of obesity.

Correspondence: S.R. Page, M.B., M.R.C.P. Accepted: 8 August 1989.
The mother's pregnancy had proceeded to term but delivery was by breech presentation. The neonatal period was complicated by feeding difficulties and generalized hypotonia. Subsequent motor development was considerably delayed. She was unable to sit independently until 18 months and did not walk until 4 years of age. Marked obesity developed from 18 months of age. She had a documented I.Q. of 84 at 5 years of age but required special schooling during adolescence; she remained grossly obese. She presented with delayed puberty and primary amenorrhoea when aged 15 years. Basal gonadotrophin concentrations were low but combined anterior pituitary function tests with luteoliberin (GnRH $100 \mu \mathrm{g})$, thyroliberin (TRH $200 \mu \mathrm{g}$ ) and insulin $(0.2 \mathrm{U} / \mathrm{kg}$ ) were normal. The gonadotrophin response to GnRH was considerably enhanced following a 6 week course of clomiphene [pre-clomiphene, peak luteinising hormone (LH) $12.4 \mathrm{mU} / 1$, peak follicle stimulating hormone (FSH) $2.3 \mathrm{mU} / 1$; post-clomiphene, peak LH $40 \mathrm{mU} / 1$, peak FSH $14.0 \mathrm{mU} / \mathrm{l}$ ]. This, together with the neonatal history, short stature (height $1.37 \mathrm{~m}$ ), massive obesity (body mass index $55.8 \mathrm{~kg} /$ $\mathrm{m}^{2}$, normal $<25 \mathrm{~kg} / \mathrm{m}^{2}$ ), small hands and feet and mild mental retardation established the diagnosis of the Prader-Willi syndrome. Oestrogen replacement therapy was commenced when she was 17 years of age but discontinued five years later due to further weight gain. Chromosomal studies using the Trypsin-Giemsa method ${ }^{6}$ confirmed the presence of a deletion of the q11.1-q11.2 region of the long arm of chromosome 15.

Her pulse was 86 per minute sinus rhythm, blood pressure $130 / 80 \mathrm{mmHg}$. The jugular venous pressure was $3 \mathrm{~cm}$ and cardiac auscultation was normal. There was no clinical evidence of pul- 
monary or peripheral oedema. A chest radiograph revealed a large cardiac silhouette and electrocardiography showed loss of anterior $\mathbf{R}$ wave amplitude. Cardiac enzymes and the blood urea and electrolytes were normal. Fasting serum cholesterol and triglycerides were $4.2 \mathrm{mmol} / \mathrm{l}$ and $1.1 \mathrm{mmol} / \mathrm{l}$ respectively (normal range; cholesterol $3.3-7.3 \mathrm{mmol} / 1$, triglycerides $0.8-2.0 \mathrm{mmol} / \mathrm{l}$ ) and the fasting blood glucose was $4.6 \mathrm{mmol} / \mathrm{l}$ (normal range $3.0-6.0 \mathrm{mmol} / \mathrm{l}$ ). An exercise electrocardiogram was terminated at stage 2 of the Bruce protocol by chest pain and exhaustion. There was no significant ST segment depression or arrhythmia. In view of the evidence suggesting ischaemic heart disease cardiac catheterization was performed. The left ventriculogram showed antero-apical akinesia consistent with myocardial infarction and angiography revealed a severe stenosis of the left anterior descending coronary artery with delayed antegrade flow to the distal vessel (Figure 1). The remaining coronary arteries were normal. Since starting diltiazem $60 \mathrm{mg}$ three times daily she has remained free of chest pain.

\section{Discussion}

Morbidity and mortality in the Prader-Willi syndrome usually result from the complications of massive obesity. Impaired pulmonary function ${ }^{7}$ and diminished responses to carbon dioxide ${ }^{8}$ are associated with the gradual development of the obesity-hypoventilation syndrome characterized by somnolence, hypoxia and carbon dioxide retention with resulting cardiorespiratory failure.' Pulmonary embolic disease ${ }^{7}$ and death following surgical procedures ${ }^{7.9}$ have been reported as other causes of morbidity and mortality though there are few post-mortem reports available in the world literature. In the present case the angiographic findings clearly demonstrate single vessel coronary artery disease associated with myocardial infarction in a female at 28 years of age. Premature coronary artery disease is not acknowledged as a cause of mortality or morbidity in any of the major reviews of this syndrome $e^{1,7,9,10}$ and we are aware of only two previous cases of premature coronary artery disease in association with the Prader-Willi syndrome in the world literature. ${ }^{4.5}$

Non-insulin dependent diabetes related to gross obesity has been reported in approximately $7 \%$ of cases of the Prader-Willi syndrome. ${ }^{1}$ Poorly controlled diabetes together with serum cholesterol concentrations near the upper limit of the normal range were considered risk factors for coronary artery disease in one of the previous case reports. ${ }^{5}$ The present case, however, had no evidence of diabetes or hypertension and the fasting blood cholesterol concentration of $4.2 \mathrm{mmol} / \mathrm{l}$ was in the

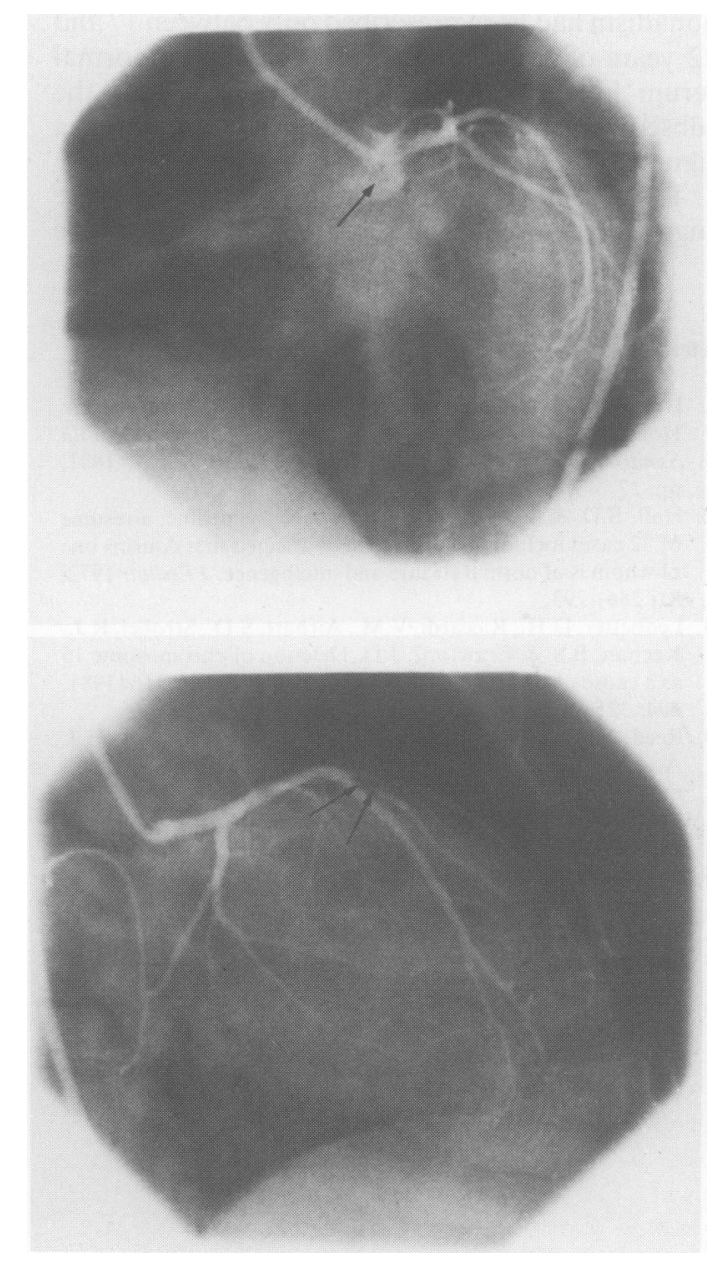

Figure 1 Left (top panel) and right (bottom panel) anterior oblique views showing severe stenosis of the left anterior descending coronary artery (arrows).

range considered optimal for the prevention of ischaemic heart disease. ${ }^{11}$ In addition there was no significant family history of heart disease. Obesity is a universal feature of patients with the PraderWilli syndrome. However, it is generally accepted in the absence of hypertension and increased serum total cholesterol concentrations, that obesity is not an independent risk factor for coronary artery disease. ${ }^{\text {I }}$ Therefore the only established independent risk factors for the development of premature coronary artery disease in the present case were a history of modest smoking ${ }^{11}$ and physical inactivity. ${ }^{12}$

Loss of endogenous oestrogens due to premature menopause is associated with an increased risk of coronary artery disease $e^{13.14}$ due in part to adverse effects on the serum lipid profile. ${ }^{15}$ In the present case, oestrogen replacement therapy for hypo- 
gonadism had been prescribed only between 17 and 22 years of age. However, in view of the normal serum lipids, we believe it is unlikely that the subsequent lack of oestrogen therapy was a significant risk factor for coronary artery disease.

The absence of significant risk factors in this case suggests that premature coronary artery disease may be a direct and largely unrecognized feature of the Prader-Willi syndrome. It is interesting to speculate that the chromosomal deletion from the q11.1-q11.2 region of the long arm of chromosome 15 which is commonly associated with the Prader-Willi syndrome may be also implicated in the development of premature arterial disease.

\section{References}

1. Holm, V.A. The diagnosis of the Prader-Willi Syndrome. In: Holm, V.A., Sulzbacher, S.J. \& Pipes, P.L. (eds) Prader-Willi Syndrome. University Park Press, Baltimore, 1981, pp. $27-45$

2. Hall, B.D. \& Smith, D.W. Prader-Willi syndrome; a resume of 32 cases including an instance of affected first cousins one of whom is of normal stature and intelligence. $J$ Pediatr 1972, 81: $286-293$.

3. Ledbetter, D.H., Riccardi, V.M., Airhart, S.D., Strobel, R.J., Keenan, B.S. \& Crawford, J.D. Deletion of chromosome 15 as a cause of the Prader-Willi Syndrome. N Engl J Med 1981, 304: 325-329.

4. Reed, W.B., Ragsdale, W., Curtis, A.C. \& Richards, H.J. Acanthosis nigricans in association with various genodermatoses with emphasis on lipodystrophic diabetes and Prader-Willi syndrome. Acta Derm Venereol (Stockh) 1968, 48: $465-473$.

5. Lamb, A.S \& Johnson, W.M. Premature coronary atherosclerosis in a patient with the Prader-Willi syndrome. Am J Med Genet 1987, 28: 873-880.

6. Seabright, M. A rapid banding technique for human chromosomes. Lancet 1971, ii: 971-972.

7. Bray, G.A., Dahms, W.T., Swerdloff, R.S., Fiser, R.H., Atkinson, R.L. \& Carrel, R.E. The Prader-Willi Syndrome: a study of $\mathbf{4 0}$ patients and a review of the literature. Medicine 1983, 62: 59-80.

8. Orenstein, D.M., Boat, T.F., Owens, R.P. et al. The obesityhypoventilation syndrome in children with the Prader-Willi syndrome. A possible role for familial decreased response to carbon dioxide. J Pediatr 1980, 97: 765-767.

9. Laurance, B.M., Brito, A. \& Wilkinson, J. Prader-Willi syndrome after 15 years of age. Arch Dis Child 1981, 56: $181-186$.

10. Cassidy, S.B. Prader-Willi Syndrome. Curr Probl Pediatr 1984, 14: 2-55.

11. Dawber, T.R. The Framingham Study. The epidemiology of atherosclerotic disease. Harvard University Press, Cambridge, Mass, 1980

12. Paffenberger, R.S., Wing, A.L. \& Hyde, R.T. Physical activity as an index of heart attack risk in college alumni. Am $J$ Epidemiol 1978, 108: 161-175.

13. Oliver, M.F. \& Boyd, G.S. The effect of bilateral ovariectomy on coronary artery disease and serum lipid levels. Lancet 1963, i: $962-965$.

14. Gordon, T., Karnel, W.B., Hjortland, M.C. \& McNamara, P.M. The menopause and coronary artery disease: The Framingham study. Ann Intern Med 1978, 89: 157-161.

15. Kannel, W.B., Hjortland, M.C., McNamara, P.M. et al. Menopause and the risk of cardiovascular disease: the Framingham study. Ann Intern Med 1976, 85: 447-452. 